\title{
Animacy and Inverse in Movima: A Corpus Study
}

\author{
KATHARINA HAUDE
}

\author{
Centre National de la Recherche Scientifique (CNRS)
}

\begin{abstract}
Coding of transitive clauses in Movima (lowland Bolivia) including a speech act participant reflects a person hierarchy, $1>2>3$; when a lowerranking person acts on a higher-ranking one, the verb is marked as inverse. This article investigates the conditions under which inverse marking occurs when a transitive clause contains only third-person arguments. A quantitative analysis of spontaneous speech data shows that, while the discourse factors involved still require further research, animacy plays an important role. For instance, inverse marking never occurs when an entity higher in the animacy hierarchy acts on a lower ranking one.
\end{abstract}

1. Introduction. This article investigates the role of animacy in the directinverse system of Movima, an unclassified, endangered language of southwestern Amazonia (Bolivia). In Movima, there is neither case nor agreement marking; instead, the linear order of constituents in transitive clauses is fixed, and participant roles are assigned by verb morphology. The ordering of the arguments depends on their referential properties, which include their relative status in a hierarchy of person and animacy, and on their discourse prominence. The participant roles of the arguments are indicated by direct or inverse marking on the verb.

The present study examines the conditions of argument coding in transitive clauses containing only third person referents. While in scenarios involving a speech-act participant, the expression of the arguments and the corresponding direct or inverse marking on the verb can be predicted from the position of the referents in the Movima person hierarchy (in which first person is highest: $1>2>3$ ), this is not the case when two third persons are involved. Here, the question is which principles determine their occurrence in either the one or the other syntactic slot. Basically, these principles are most adequately captured by DeLancey's (1981) notions of "viewpoint," which comprises animacy and discourse prominence of the referents, and "attention flow," which accounts for a tendency for forms coding the actor to precede forms coding the undergoer. Analysis of a text corpus of Movima spontaneous oral discourse shows that, while speakers are, in principle, free to choose the viewpoint from which to present an event, they usually prefer that of the actor-which is then expressed in the first position after the direct-marked predicate-but that animacy also plays an important role in this choice.

The remainder of this article is structured as follows. Section 2 presents the structure of pragmatically unmarked transitive clauses in Movima and shows 
how the person hierarchy determines the coding of the arguments and the corresponding direct or inverse marking. Section 3 deals with the structure of unmarked transitive clauses that contain two third person arguments, first illustrating how third person arguments are expressed in unmarked transitive clauses and the frequencies with which different expressions cooccur, and then analyzing the role of the animacy properties of the participants coded by the arguments in terms of a classification of the major constellations as "high-onlow," "equal," and "low-on-high" scenarios. Section 4 presents conclusions and points out some topics for further research.

2. The person hierarchy. Movima transitive clauses contain two arguments, which I label "proximate" and "obviative." The core structure of a canonical, pragmatically unmarked transitive clause (both main and subordinate) is schematized as follows:

PREDICATE=PROXIMATE(--)(OBVIATIVE)

Here, the predicate is followed by the two arguments, of which only the first (the proximate argument) is obligatorily realized, while the second (the obviative argument) can be left unexpressed. ${ }^{1}$ In addition, for pragmatic purposes the predicate can be preceded by a free personal pronoun, an NP (noun phrase), or a demonstrative (these pragmatically marked constructions are not considered here [but see Haude 2012a]). Apart from linear order, the two arguments are formally distinguished by additional factors, especially by the way in which they are attached to the preceding constituent. Their different properties are listed in table 1 (for a more detailed account, see Haude 2009, 2010a).

\section{Table 1. Formal Properties of Proximate and Obviative Arguments}

\begin{tabular}{ll}
\hline PROXIMATE & OBVIATIVE \\
internal cliticization $(=)$ : stress shift; & external cliticization ( -- ): no stress shift; \\
epenthetic a on consonant-final hosts & resyllabification with consonant-final host \\
pronouns and articles are cliticized & only pronouns are cliticized \\
obligatory $^{\dagger}$ & can be omitted
\end{tabular}

NOTE: The coding properties of the proximate argument are the same as those of adnominal possessors, while the coding properties of the obviative argument are the same as those of the single argument of an intransitive clause (see Haude 2010a).

t The absence of an overt proximate enclitic in an unmarked transitive clause unambiguously marks the first person singular (i.e., $=\varnothing$ ' $1 \mathrm{SG}$ ').

The labels "proximate" and "obviative" are borrowed from the Algonquianist tradition, where they indicate the morphologically marked difference in discourse status of two third persons. My use of this terminology for Movima (first proposed by Bickel 2011:429) is intended to imply that the coding of an event 
participant as either one or the other argument depends on its referential properties: the participant that ranks higher in terms of person and animacy hierarchies and in terms of discourse prominence is coded as proximate, and the participant ranking lower on these hierarchies is coded as obviative. This is reflected as follows: first person singular, first person plural, and second person singular can only be expressed as proximate (in clauses with a first person argument and a second person singular argument, only the first person is expressed), and the second person plural is expressed as obviative only when it cooccurs with a first person (see Haude 2011a); a third person is obligatorily expressed as obviative when cooccurring with a first or second person (see table 2). The expression of two cooccurring third persons is discussed in section 3 .

\section{Table 2. Assignment of Persons as Either Proximate or Obviative}

$\begin{array}{ll}\text { PROXIMATE } & \text { OBVIATIVE } \\ \text { 1SG/PL } & \text { 2PL; 3SG/PL } \\ \text { 2SG/PL } & \text { 3SG/PL } \\ \text { 3SG/PL } & \text { 3SG/PL }\end{array}$

Movima has neither nominal case marking nor verbal person agreement morphology. The participant roles of the arguments (actor and undergoer) are indicated by direct and inverse marking on the predicate: when the proximate argument is the actor and the obviative argument is the undergoer, the verb is marked as direct; when the proximate argument is the undergoer and the obviative argument is the actor, the verb is marked as inverse. This is illustrated in (1a)-(2b) for "mixed" scenarios, i.e., those involving a speech-act participant and a third person. (For "local" scenarios, i.e., those involving only first and second person, see Haude 2011a.)

(1a) 1 acts on 3: direct

sal-na $=\emptyset--u s$

look.for-DR=1SG--3M.AB

'I look for him.'

(1b) 3 acts on 1 : inverse

sal-kay $=\varnothing--u s$

look.for-INV=1SG--3M.AB

'He looks for me.'

(2a) 2 acts on 3: direct

sal-na=n--us

look.for-DR=2SG--3M.AB

'You look for him.' 
(2b) 3 acts on 2: inverse

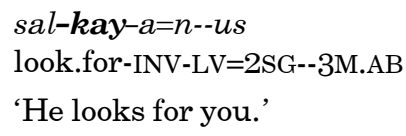

3. Nonlocal scenarios. In contrast to local and mixed scenarios, where access to the argument slots is grammatically determined, there is no grammatical restriction on the coding of arguments as either proximate or obviative for the expression of nonlocal scenarios (i.e., scenarios where both arguments are third person). The two elicited examples below illustrate this: while they both describe the same event (a snake biting a man), (3a) is a direct construction with the actor (the snake) as proximate, and (3b) is an inverse construction with the undergoer (the man) as proximate. (Here and in the remainder of this article, the inverse construction is translated with the English passive.)

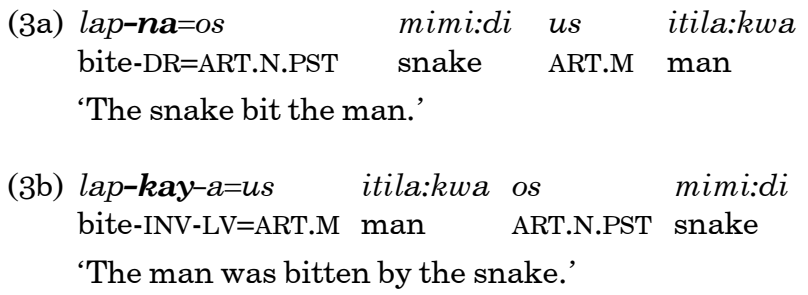

The question investigated in this article is which of the arguments is coded as proximate and which as obviative in a nonlocal scenario, or, in other words, under what conditions is either the direct or the inverse construction used to describe nonlocal scenarios in spontaneous discourse.

First of all, it is important to note that the direct construction can be considered the default transitive construction (see Haude 2010a), reflecting the cross-linguistically observed preference for actors to precede undergoers in the linear order of the clause, a preference captured by DeLancey's (1981) concept of "attention flow." In principle, the direct construction can be used to describe any nonlocal scenario. When sentences describing nonlocal scenarios are elicited, as in (3a) and (3b) above, the direct construction is always offered first, while the inverse is only accepted when proposed. Furthermore, over 90 percent of transitive predicates with two third person arguments in spontaneous discourse are direct (see tables 5 and 6 below), and, as shown in the following sections, this is not only due to the fact that most of the described scenarios accord with the hierarchies of animacy, discourse prominence, or both. However, since the inverse is found as well, the use of the inverse construction in descriptions of nonlocal scenarios merits a more thorough investigation.

The discussion below is centered around the hypothesis put forward elsewhere (Haude 2006, 2009) that the proximate argument represents the event participant that ranks higher in the animacy hierarchy, "human > (nonhuman) 
animate > inanimate." The analysis is based on a database of approximately 1,260 Toolbox records (i.e., intonation units transcribed in Toolbox) that contain unmarked transitive clauses (i.e., of the type PREDICATE=PROXIMATE(--) (OBVIATIVE)) with two third person arguments. ${ }^{2}$

3.1. Argument expressions. In unmarked transitive clauses, third persons can be expressed by bound personal pronouns or by NPs. ${ }^{3}$ Personal pronouns indicate gender and number (human masculine, human feminine, nonhuman, and plural or mass), and presence vs. absence of the referent (see table 3; in the interlinear glosses, the presential/generic category is left unglossed). They are encliticized through either internal (=) or external (--) cliticization, depending on whether they function as proximate or obviative (see table 1 above). Obviative pronouns, in this context, furthermore receive a redundant "obviative" prefix $k$-, as will be seen in some of the examples below. ${ }^{4}$

Table 3. Movima Bound Pronouns

\begin{tabular}{lcc}
\hline & PRESENTIAL/GENERIC & ABSENTIAL/PAST \\
masculine & $u^{\prime}$ & us \\
feminine & (i)'ne & (i) sne \\
nonhuman (neuter) & $a{ }^{\prime}$ & as \\
plural/mass & $i$, & is \\
\hline
\end{tabular}

A noun phrase (NP) always contains a determiner (typically an article, sometimes a demonstrative) that precedes the content word (typically a noun, sometimes a verb or adjective). The paradigm of articles is given in table 4 (again, in the interlinear glosses, the presential/generic category is left unglossed). In addition to the categories also marked on pronouns, articles also have a "past" form for referents that have ceased to exist (see Haude 2010b). Note that articles are not necessarily definite-the interpretation of an NP as definite or indefinite depends on the context. ${ }^{5}$

Table 4. Movima Articles

\begin{tabular}{lccl} 
& PRESENTIAL/GENERIC & ABSENTIAL & PAST \\
masculine & us & kus & us \\
feminine & (i)'nes & kinos & isnos \\
nonhuman & as & kos & os \\
plural/mass & is & kis & is \\
\hline
\end{tabular}

Typically, the proximate argument is a pronoun, and the most frequent pattern is as follows. In a transitive clause, the topic of the (segment of) discourse is referred to by a proximate pronoun, while the verb is marked as either direct or inverse to indicate its participant role. The proximate argument usually corefers with the argument of a preceding intransitive clause, as illustrated 
by (4) and (5). These examples stem from a mythological story in which a boy climbs up a tree to shake down its fruits, which his younger brother then picks up from the ground. Suddenly a jaguar appears and attacks the younger brother. In both examples, the discourse topic is the boy. In (4), he is referred to by the single argument (us oveniwankwa) of the first, intransitive clause (line 1, 'then the boy climbed up') and taken up by the proximate pronoun (=us) in the following, transitive inverse clause (line 2$)^{6}$

(4) 1 jayna wele:te us oveniwankwa [...]

DSC climb ART.M young.man

2 jayna julra-kay-a=us is so:te

DSC win.over-INV-LV=3M.AB ART.PL other.person

'Then the boy climbed up [. . . ] (because) he had been defeated by others (who had already collected all the fruits that were on the ground).' (HRR_120808tigregente 056-057)

About ten sentences later, the jaguar (os rulrul) has appeared and moves towards the younger brother, as described by the intransitive clause in line 1 of (5). The jaguar is then represented by the proximate pronoun (=as) of the subsequent transitive direct clause in line $2 .^{7}$
(5) 1 nat-chet tat os rulrul [...] n-os en-na=us approach-R/R EV ART.N.PST jaguar OBL-ART.N.PST stand-LOC=ART.M
[...] dichi:ye di' jot-a:-di n-is kate:na.
child REL collect-DR-CL.seed OBL-ART.PL coquino

\section{Dan-a-cho-bakwa=as.}
chew-DR-CL.inside-head=3N.AB
'The jaguar moved towards the place where the child was that was collecting the coquinos. It chewed [his] head (lit., 'it head-chewed [him]').' (HRR_120808- tigregente 077-080)

While the proximate argument is typically a pronoun and the obviative argument either an NP (as in (4)) or omitted (as in (5)), other constellations of argument expressions occur as well. The first two columns of table 5 show the frequency of the different possible constellations of pronouns, NPs, and zeros (i.e., unexpressed obviative) in the corpus. The figures in table 5 confirm that proximate arguments are usually represented by a pronoun (92 percent, the sum of the first three lines). In over half of all clauses in the corpus (55 percent), the proximate argument is a pronoun and the obviative argument an NP, the pattern illustrated in (4). Since pronouns are generally used to code entities that are known from the context, while NPs are more appropriate to introduce new discourse participants, these figures show that, not surprisingly, discourse prominence (i.e., the "accessibility" or "identifiability" of a referent; see, e.g., Chafe 1996) is highly relevant for argument coding in Movima. 
Table 5. Constellations of Argument Expressions in the Corpus of Unmarked Transitive Clauses with Third Person Interactions

\begin{tabular}{lcccccc}
\hline PROX/OBV & TOTAL & PERCENT* & DR & INV & $\%$ DR & $\%$ INV \\
pronoun / NP & 696 & $55 \%$ & 650 & 46 & $93 \%$ & $7 \%$ \\
pronoun / $~$ & 380 & $30 \%$ & 354 & 26 & $93 \%$ & $7 \%$ \\
pronoun / pronoun & 88 & $7 \%$ & 82 & 6 & $93 \%$ & $7 \%$ \\
NP / NP & 52 & $4 \%$ & 51 & 1 & $98 \%$ & $2 \%$ \\
NP / $\varnothing$ & 38 & $3 \%$ & 36 & 2 & $95 \%$ & $5 \%$ \\
NP / pronoun & 4 & $0 \%$ & 4 & 0 & $100 \%$ & $0 \%$ \\
TOTAL & 1,258 & $99 \%$ & $1,177(94 \%)$ & $81(6 \%)$ & &
\end{tabular}

*Percentages do not sum to exactly 100 percent due to rounding in Excel.

The next most common pattern is the one where the proximate argument is a pronoun and the obviative argument not overtly expressed at all (30 percent), as is illustrated in (5) above. (Note that the predicate remains fully transitive here; there are specific morphological devices to detransitivize a predicate [Haude 2012b].) While the exact circumstances under which the obviative argument can be left unexpressed require further research, a tentative account can be given here. The referent of the unexpressed obviative is usually clear from the (linguistic or extralinguistic) context, the meaning of the verb, or world knowledge. Consider (6) below. Line 2 contains two transitive clauses, which are preceded by an intransitive adverbial clause (line 1 ). ${ }^{8}$ The argument of the intransitive clause (=as 'it') can be interpreted as referring cataphorically to the unexpressed obviative argument of the second transitive predicate (man-na=us 'he shot [it]'). However, the referent of the unexpressed obviative argument of the first transitive predicate (way-na=us 'he took [it]'), which must be a gun or something similar, was not previously mentioned; it can only be inferred from the larger context, the meaning of the verb, and (culture-specific) world knowledge. I conclude that when the obviative argument is left unexpressed, this does not mean that its referent must be one that has been previously mentioned, as the literature sometimes suggests (e.g., Ariel 1990:73; Givón 2001:463). Rather, it is implicated in the event in a way that does not require its being explicitly mentioned at all.

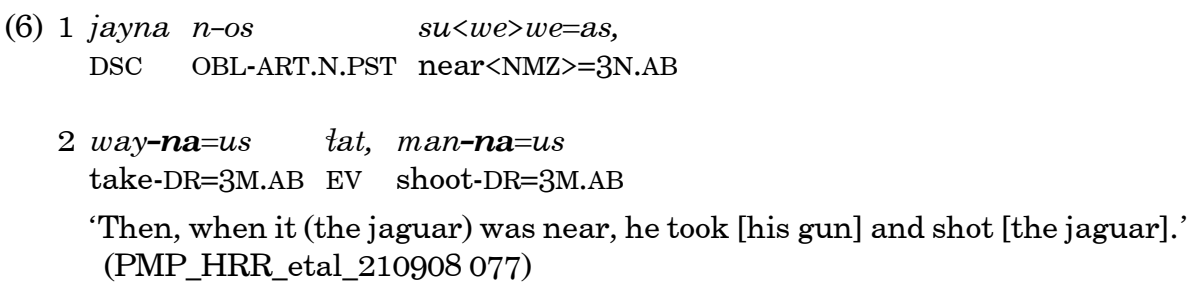

In the last four columns of table 5, the number of different argument constellations is divided into their occurrence in either the direct or inverse construction. A first, general result is that 94 percent of all transitive clauses with 
two third person arguments are direct, while only 6 percent are inverse. Judging from the percentages in the two rightmost columns, this result seems to be almost independent of the way in which the arguments are expressed. However, even though the low number of proximate NPs in the corpus, ninety-four, impedes an accurate analysis, the inverse appears to be particularly infrequent when the proximate argument is an NP. That it is grammatically possible is illustrated in (7) (see also line 2 of (3) above).

(7) ba:<ka>-lomaj-kay-a=i complete<MLT>-CL.time-INV-LV=ART.PL all.kind-CL.animal REL animal

'All kinds of animals will be finished off (by the hurricane).' (HRR_2009_tape1_A 480)

An explanation for the scarcity of such examples might be the following: the expression of the proximate argument as an NP instead of a pronoun is an indication that its referent does not outrank the obviative argument in terms of discourse prominence (or even animacy - consider (20) and (21) below, where the proximate NP denotes a nonhuman, while the obviative argument is human). Thus, there is a competition between a direct construction with a proximate NP and an inverse construction with an obviative NP; the occurrence of the former may be due to the above-mentioned general preference for the direct construction, not to a higher position of the proximate argument in the referential hierarchy.

To sum up, the proximate argument is most likely to be expressed by a pronoun, which reflects its propensity to code the participant that is most prominent in discourse. Less frequently, the proximate argument is expressed by an NP; this case is hardly ever expressed by the inverse construction, showing that word order alone can be a means to indicate participant roles.

3.2. Animacy. In the corpus, I examined the nine possible interactions of the three major animacy categories-human, (nonhuman) animate, and inanimate-counting how many of them are expressed by direct and how many by inverse constructions. I call interactions in which the higher-ranking participant in the animacy hierarchy acts on the lower-ranking one the "high-on-low scenario" and those in which the lower-ranking participant acts on a higherranking one the "low-on-high scenario." When two equally ranked participants interact, this is called the "equal scenario." The frequency of direct and inverse constructions in each scenario in the corpus is presented in table 6. The arrow symbol $(\rightarrow)$ stands for "acts on": this means that in the column for the direct construction (DR), the proximate argument is the participant on the left of the arrow, and in the column for the inverse construction (INV), the proximate argument is the participant on the right of the arrow. The higher figures are represented in bold type. 
Table 6. Different Animacy Scenarios in the Corpus of Unmarked Transitive Clauses with Third Person Interactions

\begin{tabular}{|c|c|c|c|c|c|c|c|}
\hline SCENARIO & SUBTYPE & TOTAL & PERCENT & DR & INV & $\% \mathrm{DR}$ & $\% \mathrm{INV}$ \\
\hline high-on-low & human $\rightarrow$ inanimate & 451 & $36 \%$ & 451 & 0 & $100 \%$ & $0 \%$ \\
\hline high-on-low & human $\rightarrow$ animate & 145 & $12 \%$ & 145 & 0 & $100 \%$ & $0 \%$ \\
\hline high-on-low & animate $\rightarrow$ inanimate & 146 & $12 \%$ & 146 & 0 & $100 \%$ & $0 \%$ \\
\hline equal & human $\rightarrow$ human & 300 & $24 \%$ & 260 & 40 & $87 \%$ & $13 \%$ \\
\hline equal & animate $\rightarrow$ animate & 127 & $10 \%$ & 115 & 12 & $91 \%$ & $9 \%$ \\
\hline equal & inanimate $\rightarrow$ inanimate & 5 & $0 \%$ & 3 & 2 & $60 \%$ & $40 \%$ \\
\hline low-on-high & animate $\rightarrow$ human & 62 & $5 \%$ & 39 & 23 & $63 \%$ & $37 \%$ \\
\hline low-on-high & inanimate $\rightarrow$ human & 8 & $1 \%$ & 0 & 8 & $0 \%$ & $100 \%$ \\
\hline low-on-high & inanimate $\rightarrow$ animate & 10 & $1 \%$ & 3 & 7 & $30 \%$ & $70 \%$ \\
\hline Total & & 1,254 & $101 \%$ & $\begin{array}{c}1,162 \\
(93 \%)\end{array}$ & $\begin{array}{r}92 \\
(7 \%)\end{array}$ & & \\
\hline
\end{tabular}

NOTE: The slight divergence in number from table 5 (where the total $=1,258$, and the ratio $\mathrm{DR} / \mathrm{INV}=94 \% / 6 \%$ ) is due to the way in which the Toolbox records were tagged. When in one record, several clauses describe the same scenario, this is only tagged once; but when the clauses present different constellations of argument expressions, these were tagged individually. Percentages again do not add up to 100 percent due to rounding in Excel.

3.2.1. High-on-low scenarios. As can be seen in table 6, high-on-low scenarios constitute the most common case, occurring in over half of the corpus (60 percent). Equal scenarios, usually with human or other animate participants, are relatively frequent as well (34 percent), whereas low-on-high scenarios are quite rare (7 percent). These results are not surprising, since animates, and particularly humans, are most likely to represent a speaker's viewpoint and are also typical actors. (Indeed, scenarios with human actors constitute 72 percent of the corpus.) Example (8) illustrates the linguistic expression of the most frequent scenario, where a human acts on an inanimate entity.

\section{(8) lirij-te-na=us is kate:na \\ shake-CO-DR=3M.AB ART.PL coquino \\ 'He shook down the coquino fruits.' (HRR_120808-tigregente 066)}

An important result shown by table 6 is that high-on-low scenarios in spontaneous discourse are always represented by the direct, never by the inverse construction; in other words, one never finds a lower-ranking participant as the proximate argument of an inverse predicate, of the type illustrated in (9) (accepted in elicitation).
(9) tikoy-kay-a=os mimi:di us itila:kwa
kill-INV-LV=ART.N.PST snake ART.M man
'The snake was killed by the man.'


The strong result for high-on-low scenarios is independent of the expression of the arguments. A count of a subpart of the corpus (covering the data collected since 2006, i.e., about 830 transitive clauses with two third person arguments), displayed in table 7, shows that all constellations of argument expressions occur, in a ratio similar to that for the overall corpus and all scenarios (see table 5). Therefore, the expression of the arguments cannot account for the fact that the inverse construction is never used for high-on-low scenarios.

Table 7. Expression of Arguments in High-on-Low Scenarios (Subcorpus)

$\begin{array}{lcc}\text { PROXIMATE / OBVIATIVE } & \text { NUMBER } & \text { PERCENT } \\ \text { pronoun / NP } & 241 & 58 \% \\ \text { pronoun / } \varnothing & 136 & 33 \% \\ \text { pronoun / pronoun } & 14 & 3 \% \\ \text { NP / NP } & 16 & 4 \% \\ \text { NP / } \varnothing & 8 & 2 \% \\ \text { NP / pronoun } & 1 & 0 \% \\ \text { TOTAL } & 416 & 100 \%\end{array}$

The most natural explanation for the absence of the inverse construction from descriptions of high-on-low scenarios is that the lower-ranking event participant is usually not the most prominent in discourse. Nevertheless, there are indications that the absence of exceptions also has to do with animacy, independently of discourse prominence. In stories with animals as main protagonists (which are always referred to with the nonhuman pronouns and articles; see section 3.1 above), the inverse construction is never used when the animal undergoes an event induced by a human. Only the direct construction is used to express this kind of scenario, as illustrated in (10) and (11). Example (10) comes from a story about Movima cattle, and the cattle might therefore be considered prominent in the discourse. Still, in the transitive clause in line 2, the human actors (not specified in the preceding discourse) are coded as proximate $(=i)$ and the cows are coded as obviative (-- $\left.k-i^{\prime}\right)$ of the direct-marked predicate.

(10) 1 asko jayna bijaw-ni-na=i, kis ney wa:ka jayna, PRO.N.AB DSC old-PRC-LOC=3PL ART.PL.AB here cow DSC

2 wa: rey di jayna bot-ra-na $=i--k-i$ ' even.if MOD HYP DSC replace-BE.NTR-DR=3PL--OBV-3PL

'This is where they were raised, these cows, even if they (i.e., their actual keepers; unspecified) replaced them.' (ATL_230806 288-89)

In (11), from a mythological story involving a jaguar (see also (4) and (5)), the jaguar is coded in line 1 by a demonstrative pronoun (oso') in topic position (a construction not discussed here), a position that is largely reserved for obviative arguments, and the human actors are, again, coded as the proximate argument 
of the direct-marked predicate in line 2. The intransitive clause in line 1 is provided in order to demonstrate that the jaguar can be considered the topic of this stretch of discourse.

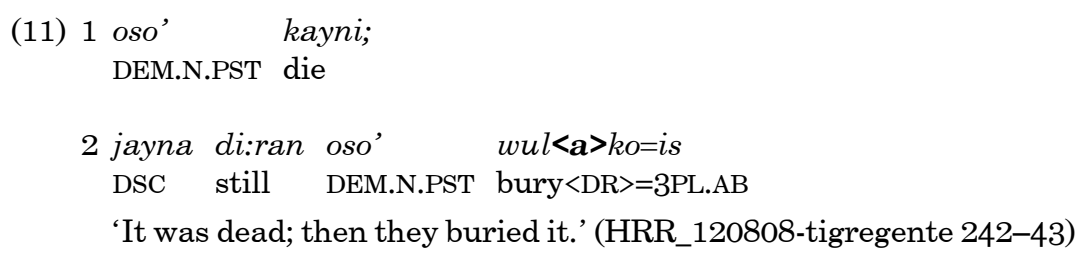

3.2.2. Equal scenarios. If a transitive clause is by default direct (see the introduction to section 3), on the one hand, and the animacy hierarchy plays a role in the choice of the direct or the inverse construction, on the other, it is surprising that the inverse occurs relatively often in descriptions of so-called equal scenarios (i.e., scenarios in which both participants rank equally on the animacy hierarchy), as can be observed in table 6. A text count (see table 8) of the subpart of the corpus introduced in section 3.2.1 above shows that despite the low total frequency, inverse constructions are not even restricted to nonequal argument expressions. (Table 8 shows only the cases where the proximate argument is a pronoun, since the inverse occurs only here; see table 5 above.)

Table 8. Direct and Inverse in Equal Scenarios according to Argument Expressions (Subcorpus)

\begin{tabular}{lcrrc}
\hline PROXIMATE / OBVIATIVE & TOTAL & DR & INV & $\%$ INV \\
pronoun /NP & 125 & 111 & 14 & $11 \%$ \\
pronoun / $\varnothing$ & 105 & 95 & 10 & $10 \%$ \\
pronoun / pronoun & 12 & 10 & 2 & $17 \%$ \\
TOTAL & 272 & 246 & 26 & $10 \%$ \\
\hline
\end{tabular}

It might be expected that in equal scenarios, the inverse occurs only when the proximate argument is a pronoun and the obviative argument is not, i.e., that the use of the inverse is conditioned by the expression of the arguments (as was suggested in Haude [2010a] on the basis of insufficient text data). Examples of this expected situation are given in (12), with two inanimate participants, and in (13), with two animate participants. ${ }^{9}$

(12) jayna tadoy-kay-a=is os dan-n-et-wa=is

DSC sweet-INV-LV=3PL.AB ART.N.PST chew-LN-AGT-NMZ=3PL.AB

'(They didn't need to sweeten their chicha because) it was already sweetened by their chewing.' (HRR tx 288)

(13) jayna tat $n$-os buka' iloni-wa=as n-os DSC EV OBL-ART.N.PST DUR:move walk-NMZ=3N.AB OBL-ART.N.PST 
bet'i ba:lowes-kay-a=as tat os tuspak

grassland reach-INV-LV=3N.AB EV ART.N.PST vulture

'Then, as it (the fox) was walking through the grassland, it was reached by the vulture.' (HRR_2009_tape1_B 122-23)

In contrast, when the two participants are expressed by equal forms (e.g., pronouns) and can therefore be considered as being equal in terms of discourse prominence, one might expect the default direct construction. This is indeed the case in (14), where despite the change of the participant roles in two consecutive transitive clauses (lines 1 and 2), the direct form is chosen in both.

(14) 1 jayte jayna di' yey-na='ne, jay<a $>$ mot-a='ne-- $k$-isne then DSC HYP want-DR=3F call $<\mathrm{DR}>-\mathrm{LV}=3 \mathrm{~F}-\mathrm{-OBV}-3 \mathrm{~F} \cdot \mathrm{AB}$

2 che di' rey isne yey-na=sne, jay<a>mot-a=sne--k-i'ne. and HYP MOD PRO.3F want-DR=3F.AB call $<\mathrm{DR}>-\mathrm{LV}=3 \mathrm{~F} . \mathrm{AB}-\mathrm{OBV}-\mathrm{PRO} .3 \mathrm{~F}$

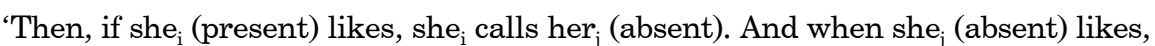
she $_{\mathrm{j}}$ calls her ${ }_{\mathrm{i}}$ (present).' (EAO Dialogue 059)

However, the inverse can also occur even when an equal scenario is described with similar argument expressions, as is exemplified in (15). (Note that in the entire corpus, all examples of this kind involve only human participants, reflecting the higher tendency for human discourse participants to be pronominalized; see Dahl and Fraurud 1996). The explanation that can be offered for this example is that the proximate argument $(=i s)$ refers to the Movima people, who are likely to represent the speaker's viewpoint and who were also the topic of the previous discourse (as reflected by the use of the pronoun --is also in the first, intransitive sentence in line 1 of (15)). Hence, the choice of the inverse construction here is based on discourse prominence, and the way in which the arguments are expressed does not suffice by itself to predict whether the direct or the inverse construction will be used.
(15) 1 jayna $n$-os ji<wa: > wa--is, jayna $n$-os DSC OBL-ART.N.PST come $<\sim$ MD $>3$ PL.AB DSC OBL-ART.N.PST
'When they came, when the priest arrived, they were assembled by him here.' (HRR_120808-tigregente 031-032)

Thus, the inverse construction is not infrequent with equal scenarios, and there is no direct link between its occurrence and the way in which the arguments are expressed. Its use is governed by discourse factors, and more research is required in this domain. 
3.2.3. Low-on-high scenarios. Table 9 (excerpted from table 6) shows that low-on-high scenarios involving inanimate entities are predominantly expressed with the inverse construction.

Table 9. Low-on-High Scenarios in the Corpus of Unmarked Transitive Clauses with Third Person Interactions

\begin{tabular}{|c|c|c|c|c|c|c|c|}
\hline SCENARIO & SUBTYPE & TOTAL & PERCENT & DR & INV & $\% \mathrm{DR}$ & $\% \mathrm{INV}$ \\
\hline & & 62 & $5 \%$ & 39 & 23 & $63 \%$ & $37 \%$ \\
\hline & inar & 8 & $1 \%$ & 0 & 8 & $0 \%$ & $100 \%$ \\
\hline low-on-high & inanimate $\rightarrow$ animate & 10 & $1 \%$ & 3 & 7 & $30 \%$ & $70 \%$ \\
\hline
\end{tabular}

An example of such scenarios is given in (16).

(16) bak-kay-a=is os sarampiyon

pick-INV-LV=3PL.AB ART.N.PST measles

'They (the settlers) got infected by the measles.' (JGD_160808-Fundacion-02 447)

The three examples in the corpus in which the direct construction expresses an inanimate acting on an animate can be accounted for by adjustments of the animacy hierarchy-in all of them, the actor is a natural force, as in (17). Since it is not unusual cross-linguistically for natural forces to be ranked above other inanimates, it might be more adequate to consider this an equal rather than a low-on-high scenario. Note that the same scenario can also be described with the inverse construction, as is illustrated in (7) above (which is from a few sentences earlier in the same text as (16)); this means that in any case, natural forces do not outrank animates.

(17) ban is loy rey sup-te:-wa, jaa rey kavuj-ka-te-na=a

but ART.PL NEG.SUB MOD tie-CO-NMZ IJ MOD blow-MLT-CO-DR=3N

'But those who are not tied (onto something), ah!, it (i.e., the hurricane) takes [them] with it.' (HRR_2009_tape1_A 486)

The consequence of considering scenarios involving animates and natural forces as equal is that in the corpus, all low-on-high scenarios involving inanimates are expressed by the inverse construction.

Still, the result for low-on-high scenarios with an inanimate participant are less significant than the result given above for high-on-low scenarios; there are only relatively few examples, and in none of them can the the inanimate participant be considered more discourse-prominent than the animate. This is also supported by the fact that in all examples, the human or animate proximate argument is expressed as a pronoun and the inanimate obviative argument as an NP, as in (16) above. Therefore, while there are strong indications that the inverse is banned for the expression of high-on-low scenarios (see section 3.2.1), the indications that the absence of the direct construction is due to animacy are 
less strong; the use of the inverse here might just as well be due to discourse factors, similar to its use in equal scenarios (see section 3.2.2).

Table 6 also shows that the scenario in which a nonhuman animate acts on a human is not restricted to the inverse; on the contrary, the direct construction, with the nonhuman participant coded as proximate, is considerably more common (63 percent). In some cases, this can be explained by discourse factors. In (18), for instance, the nonhuman participant is expressed by a pronoun and the human by an NP, reflecting their relative discourse status in this particular stretch of discourse (see (5) above, from the same section of this text); recall from section 3.1 that a pronoun is commonly coded as proximate. The same is true of line 2 of (19)), where the nonhuman actor (a parrot, as mentioned in line 1) is coded by a proximate pronoun and the human undergoer by an obviative NP. (Note that the transitive clause in line 1 of (19) contains a first person, which is obligatorily coded as proximate.)

(18) jom $<\mathbf{a}>$ ni=as tat us dichi:ye

devour $<$ DR $>=3 \mathrm{~N} . \mathrm{AB}$ EV ART.M child

'It (the jaguar) devoured the boy.' (HRR_120808-tigregente 083)

(19) 1 os awaro da' pasinet-kay $=\varnothing$,

ART.N.PST parrot DUR.NSTD listen-INV=1SG

2 pasinet-na=as isnos senyo:ra

listen-DR=3N.AB ART.F.PST señora

'I was listened to by the parrot, (and) it listened to the lady.' (JMH Loro 029)

In both (20) and (21), the proximate argument is an NP referring to the nonhuman participant (is bi:law 'the fishes' and os diya:vlo 'the devil' respectively), and as shown in section 3.1, proximate NPs hardly ever occur in an inverse construction. It is not clear why these events are not expressed with the inverse, i.e., jayna jommi-kay-a=sne is bi:law 'She had already been devoured by the fishes' for (20) and vat-pa-kay-a=us os diyavlo 'He had been taught by the devil' for (21). This, again, must be due to the fact that the direct construction is generally preferred over the inverse.

(20) jayna isnos tolkosya jayna ka:, jayna jom $<\mathbf{a}>n i=i s$

DSC ART.F.PST girl DSC not.be DSC devour $<$ DR $>=$ ART.PL

bi:law jayna

fish DSC

'The girl wasn't there anymore, the fishes had devoured [her] already.'

(JGD_130907-06 274)

(21) vat-a-pa=os diya:vlo--k-us n-os ba:ra

appear-DR-APPL=ART.N.PST devil--OBV-3M.AB OBL-ART.N.PST all 
kilmo-wa:nas

mischievous-INSTR.ABSTR

'The devil taught him all kinds of mischief.'10 (LYO_250808_2 277)

Of the six occurrences in the corpus of inverse clauses with two pronominal arguments, four are direct and two are inverse, and there is no immediate explanation for this. Both (22) and (23) describe a similar event, even using the same verb root (lap- 'bite'); in both examples, the animal is mentioned in the immediately preceding clause, but the human is already known from the larger context. The difference in the ways in which the events are presented may be due to differences in perspective. The event described in (22) was witnessed by the speaker herself, and this might be the reason why she does not take the perspective of one of the event participants and uses the default direct construction instead; in (23), by contrast, the speaker renarrates an event she was told of by the woman that was bitten, and this might be what triggers the coding of the protagonist as proximate and the use of the corresponding inverse construction.

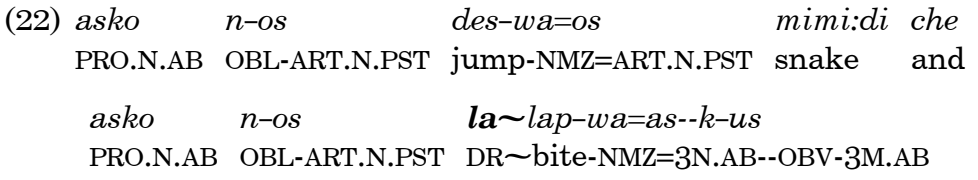

'That was when the snake jumped, and that was when it bit him.'

(EAO_240807_vbr 094)

(23) da' day-tabat os karawa:chi n-os

DUR.NSTD lie-BE.ground ART.N.PST gecko OBL-ART.N.PST

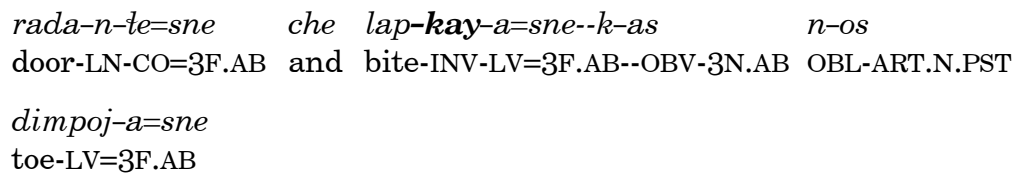

'A gecko was sitting on the ground in her doorway, and she was bitten by it in her toe.' (EAO lagartija)

A still more striking example showing that the direct construction is fully acceptable for the animate-acting-on-human scenario is presented in (24) (judged to be acceptable also by a second consultant). As in the two previous examples, both participants are expressed by bound pronouns, one referring to a man (us, 3M.AB) and the other referring to a jaguar (as, 3N.AB). From the preceding context, which describes a fight between the two, it cannot be determined which one might be more prominent, and this equal status is reflected by the use of pronouns for both. However, the expectation would be that, at least within one sentence, proximate assignment would be maintained for the same participant (actor with the first predicate, undergoer with the second predicate, so that the latter would be inverse). Instead, both predicates are direct, with the 
actor as proximate. Example (25) occurs in a similar context but is inverse, showing that the choice of direct or inverse is not determined by the lexical verb or the general propositional content.

(24) $d i$ ' nan<a>ra=us-- $k$-as rey yok-na=as-- $k-u s$

HYP set.free $<D R>=3 M . A B--O B V-3 N . A B$ MOD catch-DR=3N.AB--OBV-3M.AB

'If he let it (the jaguar) go, it would catch him.' (LYO_250808_2 075)

(25) bu'ni yok-kay-a=us os rulrul

perhaps catch-INV-LV=3M.AB ART.N.PST jaguar

'(If he went hunting alone,) he might get caught by a jaguar.' (EAO Jaguar 213)

The high frequency of direct constructions in animate-acting-on-human scenarios can be ascribed to the preference for the direct construction in general. It might also be argued that the difference between humans and nonhuman animates is not significant in Movima, so that this scenario might be of the equal rather than of the inverse type. However, the expression of the opposite scenario (human acting on animate) is fully in line with the other high-on-low scenarios in that it is never expressed by the inverse construction in spontaneous discourse (see section 3.2.1, examples (10) and (11)). Furthermore, in comparison to equal scenarios, the percentage of inverse constructions for the animate-actingon-human scenario is relatively high (37 percent). Finally, although the direct construction is frequently used, there are examples from texts in which animals as main protagonists, and these are coded as the obviative argument of an inverse construction when they act on a human. For instance, example (26) comes from a text about a dog that is proximate in all preceding direct constructions that describe it acting on objects or on other dogs. However, when a human enters the scene, the dog is coded as obviative and the human as proximate in all subsequent clauses. (Like all other inverse examples, these clauses are translated here with the English passive.)

(26) Jayte jayna potmo us pa:toron-a=y'ti di' Alejandro. [...]

then DSC get.up ART.M boss-LV=1PL REL Alejandro

Jayte os pa:ko, kajte-kay-a=us os pa:ko.

then ART.N.PST dog meet-INV-LV=3M.AB ART.N.PST dog

Chaywa-kay-a=us, “ $m m$," jankwa=os pa:ko.

answer-INV-LV=3M.AB “mm” say=ART.N.PST dog

Jayte chuspa-kay-a=us n-os charki.

then show-INV-LV=3M.AB OBL-ART.N.PST charque

'Then our boss, Alejandro, got up. ["What are you doing?" he asked.] Then the dog, he was greeted by the dog. He was answered, "mm," said the dog. Then he was shown the dried meat (by the dog).' (JMH Perro II 041-045) 
Thus, as we saw in section 3.2.1 above, in a human-acting-on-animate scenario the human is always the proximate argument of the direct predicate, even if the animal is (also) a major protagonist of the story. In the animate-acting-onhuman scenario, in contrast, there is a slight preference for the animal to be coded as proximate (63 percent), which points towards the overall preference of the direct construction with the actor as proximate. Still, the inverse construction occurs more often here than in equal scenarios. Therefore, although the text counts are apparently indeterminate, there is a general preference for humans to be represented as proximate. It can thus be maintained that low-on-high scenarios are particularly likely to be described with the inverse construction, in accord with the animacy hierarchy.

4. Conclusions and outlook. This article has investigated the role of animacy in Movima unmarked transitive clauses in actual speech. From elicitation, it was determined that animacy does not pose any restrictions on the employment of the direct or inverse construction in Movima. However, a count of approximately 1,260 transitive clauses with two third person participants in spontaneous discourse shows that the hierarchy "human $>$ nonhuman animate $>$ inanimate" is reflected by argument coding and by the corresponding use of the direct or inverse construction. Clauses in which a higher-ranking event participant acts on a lower-ranking one are always expressed with the direct construction, where the actor is coded as proximate, while clauses in which a lowerranking event participant acts on a higher-ranking one are predominantly expressed with the inverse. More specifically, with the exception of natural forces, which seem to be treated as animates, inanimate entities are always expressed as obviatives in nonequal (i.e., high-on-low and low-on-high) scenarios.

At the same time, two other factors play a role as well. First of all, the choice between the direct and the inverse construction allows the speaker to code as proximate that argument whose viewpoint the speaker is taking in a particular stretch of discourse; this is particularly apparent in clauses where the two participants are on the same level of the animacy hierarchy. The opposition between the direct and the inverse construction in Movima is, therefore, adequately analyzed as a voice opposition (see Givón 1994; Gildea 1994; Haude 2012b).

Naturally, the participant whose viewpoint the speaker takes tends to be higher in the animacy hierarchy (see, e.g., Comrie 1989; DeLancey 1981; Kuno and Kaburaki 1977), and, therefore, it remains uncertain whether the results for the nonequal scenarios, too, might in fact be primarily due to discourse factors. In order to answer this question, it would be necessary to employ a consistent method to identify the discourse topic (such as Givón's [1983] counting method). A potential study that might shed more light on the value of the results presented here would compare the use of the inverse in Movima and the interaction of the passive voice with animacy in spoken English or German. Here as well, the subject of a passive clause with an overt agent has a strong tendency to be 
high in the animacy hierarchy, and it would be interesting to see if in a comparable corpus the ratio of such passive constructions to describe high-on-low scenarios would be zero as well. ${ }^{11}$ The evidence found in the present investigation, however, shows that animacy and discourse prominence are strongly intertwined: examples like (10) and (11), where the apparently less discourseprominent participant is treated as proximate in line with the animacy hierarchy, indicate that the higher-ranking referent has a particularly strong predisposition for being treated as a discourse topic.

Furthermore, there is a strong tendency to prefer the direct construction, as is evident in elicitation and also reflected by the text counts. In the direct construction, the expression coding the actor is placed in first position after the predicate; the predominance of this construction thus accords with DeLancey's (1981) notion of "attention flow," which predicts that the actor tends to be mentioned before the undergoer. The preference for the direct construction to override animacy, discourse status, and preferences for grammatical expression was illustrated by (20), where the protagonist of the story is acted upon by fishesunlikely actors that did not previously form a topic of discourse in the story.

An issue not dealt with in this article is the influence of the lexical properties of the verb. It might be the case that the instances where the direct construction appears instead of the expected inverse involve events of strong impact, as, e.g., the catching in (24). ${ }^{12}$ However, as far as the present investigation goes, no such tendencies could be discerned.

Another topic that deserves further research is the role of animacy in constructions other than unmarked transitive clauses. Transitive verbs in relative clauses, in the marked-topic construction, and inside an NP (see Haude 2010a) grammatically require either direct or inverse marking depending on the participant role of the relativized, topicalized, or nominalized participant. However, the inverse can be avoided by using a detransitivizing construction, and the choice of the detransitivizing construction over the inverse needs to be investigated to determine if animacy has something to do with it.

\section{Notes}

Acknowledgments. I wish to thank the Institut National des Langues et Civilisations Orientales (INALCO) and the Institut de Recherche pour le Développement (IRD) for funding my research at Structure et Dynamique des Langues (SeDyL)/(UMR8202 of the Centre National de la Recherche Scientifique [CNRS]). The research on which this article is based was funded by the Deutsche Forschungsgemeinschaft (grant no. HA-5910/1-1) as part of the collaborative project "Referential Hierarchies in Morphosyntax" of the European Science Foundation. The data were collected during the projects "Lexicon and Syntax" (Radboud University Nijmegen, 2001-6) and the DoBeS (Documentation of Endangered Languages) project on Movima, funded by the Volkswagenstifung (Az. II/81914 and II/84349; see http://dobes.mpi.nl/projects/movima/). It is integrated in the program "Investissements d'Avenir," overseen by the French National Research Agency (ANR-10-LABX-0083 [Labex EFL]). I wish to thank the speakers of Movima for sharing their knowledge with me. For helpful comments on this article, I thank 
Evangelia Adamou, Jimena Terraza, and two anonymous reviewers, as well as the participants in the workshop "The Effects of Animacy Hierarchies in Native Languages of the Americas" at the Fifty-Fourth International Congress of Americanists in Vienna, 15-20 July 2012. I am grateful to Bodo Winter for his advice on the statistical evaluation of the data presented here. Needless to say, all shortcomings are entirely my own.

Symbols and abbreviations. For the codes indicating the sources of examples, see n. 2. The following symbols and abbreviations are used in examples, tables, and grammatical glosses: = internal cliticization; -- external cliticization; $\sim$ reduplication; < > infixation; $\rightarrow$ "acts on" (see table 6 in section 3.2); $1=$ first person; 2 = second person; $3=$ third person; $\mathrm{AB}=$ absent; $\mathrm{AGT}=$ agentive; $\mathrm{APPL}=$ applicative; $\mathrm{ART}=$ article; $\mathrm{BE}=$ bound nominal element; $\mathrm{CL}=$ classifier; $\mathrm{CO}=$ coparticipant; $\mathrm{DEM}=$ demonstrative; $\mathrm{DR}=$ direct; $\mathrm{DSC}=$ discontinuous; $\mathrm{DUR}=$ durative; $\mathrm{EV}=$ evidential; $\mathrm{F}=$ feminine; $\mathrm{HYP}=$ hypothetical; $\mathrm{IJ}=$ interjection; INSTR.ABSTR = abstract instrumental; INV = inverse; LN = linking nasal; $\mathrm{LOC}=$ locative nominalizer; $\mathrm{LV}=$ linking vowel; $\mathrm{M}=$ masculine; $\mathrm{MD}=$ middle voice; $\mathrm{MLT}=$ multiple event; MOD = modal; $\mathrm{N}=$ neuter; NEG.SUB = negator of subordinate; $\mathrm{NMZ}=$ nominalizer; NSTD = nonstanding; NTR = neutral; OBL = oblique; OBV = obviative; PL = plural; $\mathrm{PRC}=$ process; $\mathrm{PRO}=$ free personal pronoun; $\mathrm{PROX}=$ proximate PST $=$ past; $\mathrm{REL}=$ relativizer; $\mathrm{R} / \mathrm{R}=$ reflexive/reciprocal; $\mathrm{SG}=$ singular.

Transcription. The orthography used for the Movima examples is phonologically based. The apostrophe represents the glottal stop.

1. In negated main clauses and in most types of subordinate clause (see Haude [2006:473-74] for exceptions), the verb is nominalized, but its argument structure is the same as in main clauses.

2. This database of unmarked transitive clauses with two third person arguments was extracted from a total corpus containing data from twenty-three different speakers, totaling over twenty-six thousand Toolbox records (approximately thirty hours of recording, or 135,000 words). The data evaluated here, which are restricted to third person transitive events, consist almost exclusively of narrative discourse ranging from personal anecdotes through reported events to mythological stories. While the transcription was mainly based on intonation and only partly based on syntax, one "record" (i.e., annotation unit) in Toolbox corresponds roughly to one clause. The parenthesized source codes after each text example (e.g., (HRR_120808-tigregente 066)) refer to the speaker (here HHR), the date or the name of the text (or both, as in this example), and the Toolbox record number(s) of the text (066), enabling the example to be located in the DoBeS (Documentation of Endangered Languages) Movima corpus within The Language Archive (TLA) (https://corpus1.mpi.nl).

3. The coding of arguments by free personal pronouns and demonstratives is largely restricted to pragmatically marked constructions, which are not dealt with here.

4. The "obviative" prefix occurs only when the proximate argument is a third person or the first person plural exclusive (see Haude 2006:279).

5. The particle ney 'here' can be inserted after the absential or past article to indicate definite reference (Haude 2006:142).

6 . Note that the intransitive subject is coded like the the obviative argument of the transitive clause and also shares its syntactic properties with it (see Haude 2009, 2010a). This issue is not further pursued in this article.

7. Verbs with incorporated body parts, when marked as direct or inverse, are fully transitive.

8. In intransitive subordinate clauses, which involve a nominalized predicate, the single argument is coded like a possessor, i.e., in the same way as a proximate argument (see Haude 2011b). 
9. In (12), the first bound pronoun =is, cliticized to the inverse predicate, refers to the chicha (manioc beer; liquids are coded as plural in Movima), while the second one, a nominal possessor, refers to the people who do the chewing that acts on the chicha. (Intransitive nominalized predicates in subordinate clauses receive possessor marking; see note 8.)

10. Most Movima three-participant verbs, such as 'give', 'show', or 'teach', assign core argument status to the recipient and oblique status to the theme (Haude 2012c).

11. This is not likely. Experimental studies have shown that in German, the passive is used (although not frequently) to describe even high-on-low scenarios (see van Nice and Dietrich 2003).

12. This was suggested by Jimena Terraza (p.c. 2014).

\section{References}

Ariel, Mira

1990 Accessing Noun-Phrase Antecedents. London: Routledge.

Bickel, Balthasar

2011 Grammatical Relations Typology. In The Oxford Handbook of Linguistic Typology, edited by Jae Jung Song, 399-444. Oxford: Oxford University Press.

Chafe, Wallace

1996 Inferring Identifiability and Accessibility. In Reference and Referent Accessibility, edited by Thorstein Fretheim and Jeanette K. Gundel, 37-46. Amsterdam: John Benjamins.

Comrie, Bernard

1989 Language Universals and Linguistic Typology: Syntax and Morphology. 2nd ed. Chicago: University of Chicago Press.

Dahl, Östen, and Kari Fraurud

1996 Animacy in Grammar and Discourse. In Reference and Referent Accessibility, edited by Thorstein Fretheim and Jeanette K. Gundel, 47-64. Amsterdam: John Benjamins.

DeLancey, Scott

1981 An Interpretation of Split Ergativity and Related Patterns. Language 57(3):626-57.

Gildea, Spike

1994 Semantic and Pragmatic Inverse: "Inverse Alignment" and "Inverse Voice” in Carib of Surinam. In Voice and Inversion, edited by Talmy Givón, 187230. Amsterdam: John Benjamins.

Givón, Talmy

1983. Topic Continuity in Discourse: A Quantitative Cross-Language Study. Amsterdam: John Benjamins.

1994 The Pragmatics of De-Transitive Voice: Functional and Typological Aspects of Inversion. In Voice and Inversion, edited by Talmy Givón, 3-44. Amsterdam: John Benjamins.

2001 Syntax: An Introduction. Vol. 1. Rev. ed. Amsterdam: John Benjamins.

Haude, Katharina

2006 A Grammar of Movima. Ph.D. diss., Radboud University Nijmegen. http://webdoc.ubn.ru.nl/mono/h/haude_k/gramofmo.pdf.

2009 Hierarchical Alignment in Movima. International Journal of American Linguistics 75(4):513-32. 
2010a The Intransitive Basis of Movima Clause Structure. In Ergativity in Amazonia, edited by Spike Gildea and Francisco Queixalós, 285-315. Amsterdam: John Benjamins.

2010b "She Kisses Her Late Husband" = "She Kissed Her Husband": Nominal Tense in Movima. In Rara and Rarissima: Documenting the Fringes of Linguistic Diversity, edited by Jan Wohlgemuth and Michael Cysouw, 95-116. Berlin: Mouton de Gruyter.

2011a Argument Encoding in Movima: The Local Domain. International Journal of American Linguistics 77(4):559-71.

2011b Referring to States and Events: Subordination in Movima. In Subordination in South American Languages, edited by Rik van Gijn, Katharina Haude, and Pieter Muysken, 141-68. Amsterdam: John Benjamins.

2012a Saillance inhérente et saillance discursive en movima. Faits de Langues 39:169-80.

2012b Undergoer Orientation in Movima. In Ergativity, Valency, and Voice, edited by Gilles Authier and Katharina Haude, 259-88. Berlin: De Gruyter Mouton.

2012c The Expression of Three-Participant Events in Movima. Linguistic Discovery 10(3):80-96.

Kuno, Susumu, and Etsuko Kaburaki

1977 Empathy and Syntax. Linguistic Inquiry 8(4):627-72.

van Nice, Kathy Y., and Rainer Dietrich

2003 Task Sensitivity of Animacy Effects: Evidence from German Picture Descriptions. Linguistics 41(5):825-49. 